\title{
What is an appropriate urodynamic bladder capacity in infants?
}

\author{
Israel Franco, MD \\ Vascular Surgery, Pediatric Urology Associates, Stamford, CT; and Section of Pediatric Urology, New York Medical College, Valhalla, NY
}

See related article on page 329.

Cite as: Can Urol Assoc J 2014;8(9-10):333. htrp://dx.doi.org/10.5489/cuaj.2296

Published online October 13, 2014.

l $\mathrm{n}$ this issue of CUAJ, Costa and colleagues have developed a formula that is derived from urodynamic studies in children that were suspected to have tethered cords. ${ }^{1}$ The authors concluded that this measure of urodynamic maximal bladder capacity is a true bladder volume. Unfortunately this assertion is flawed since they did not perform natural fill urodynamics. We understand that the stresses of the procedure can have a direct effect on maximal bladder volume and sensation to void. The work that has been done by Derek Griffiths and his group and Clare Fowler and her group point to the frontal lobes playing a critical role in sensation of bladder filling. ${ }^{2}$ These very areas of the brain are very susceptible to the effects of stress. Exogenous stressors, a catheter in the bladder and unnatural filling of the bladder can render the bladder sensory apparatus to not function the way it should in this unnatural situation thereby altering the perception of filling. It does not make a difference that these are not toilet-trained children, the threshold to trigger a bladder contraction is lowered by these exogenous factors. This would explain why the results obtained in this study were all lower than in all other studies.

The authors should focus on the fact that they have defined a very important and useful parameter that is lacking in the literature - what is the normal urodynamic bladder capacity? The other studies do not address this problem and clearly we need a good way to estimate bladder capacity in these children for clinical trials and other studies.
The authors contention that their formula is better that the Holmdahl, ${ }^{3}$ Chung ${ }^{4}$ or Fairhurst ${ }^{5}$ studies is imperfect since there is a difference in patients that have a catheter in the bladder and are undergoing a strenuous procedure, such as urodynamics and the non-invasive means used to measure bladder capacity in the other studies. Nonetheless we need this data for future studies to have a good baseline to calculate expected bladder capacity in children undergoing urodynamics.

Competing interests: Dr. Franco is a member of the Speaker's Bureau for Salix. He is also currently participating in clinical trials with Astellas and Allergan.

This paper has been peer-reviewed.

\section{References}

1. Costa DFG, Lavallée LT, Dubois C, et al. Are we accurately predicting bladder capacity in infants? Can Urol Assoc J 2014;8:329-32. http://dx.doi.org/10.5489/cuai.2102

2. Fowler CJ, Griffiths DJ. A decade of functional brain imaging applied to bladder control. Neurourol Urodyn 2010;29:49-55. http://dx.doi.org/10.1002/nau.20740

3. Holmdahl $G$, Hanson $E$, Hanson $M$, et al. Four-hour voiding observation in healthy infants. J Urol 1996;156:1809-12. http://dx.doi.org/10.1016/S0022-5347(01)65543-5

4. Chung J, Kim K, Kim S, et al. Evaluation of bladder capacity in Korean children younger than 24 months: A nationwide multicenter study. World J Urol 2013;31:225-8. http://dx.doi.org/10.1007/ s00345-011-0762-4

5. Fairhurst J, Rubin C, Hyde I, et al. Bladder capacity in infants. J Pediatr Surg 1991;26:55-7. http:// dx.doi.org/10.1016/0022-3468(91)90426-T

Correspondence: Dr. Israel Franco, Vascular Surgery, Pediatric Urology Associates, Stamford, CT; isifranco@gmail.com 